\title{
LA SEDUCCION DE CELESTINA Y EL HONOR DE MELIBEA EN LA RECEPCION DE FELICIANO DE SILVA
}

\author{
Francisco Rodríguez Cascante \\ Université de Montréal
}

A Félix Carrasco, erudito lector de 'Celestina'.

\section{Introducción.}

Uno de los aspectos más interesantes de Celestina (1499) de Fernando de Rojas es el testimonio que da de las transformaciones en la manera de ver el mundo de los intelectuales de finales de la Edad Media. El texto de Rojas es una escritura plena de contradicciones, donde afloran los cuestionamientos al paradigma religioso, científico, filosófico y humano vigente en el período medieval. Sus personajes encarnan estas interrogantes y cada uno de ellos aparece como una conciencia independiente que valora y cuestiona. Lejos de actores fijados de antemano, son personalidades complejas que se mueven gracias a sus propios intereses, poniendo en duda un mundo que avanzaba hacia el Renacimiento, y con ello, a nuevas formas de percepción de las relaciones humanas y de comprensión de la realidad.

Dentro de la compleja estructura de relaciones entre los personajes, sobresale la que se establece entre Celestina y Melibea, debido a que sus diálogos están impregnados de las transformaciones que señalo. El presente artículo tiene como objeto de estudio las estrategias de seducción de Celestina y el problema del honor en Melibea, para posteriormente analizar la lectura que de estos aspectos efectuó una imitación del texto de Rojas: la Segunda Celestina (1534) de Feliciano de Silva, con el fin de observar la recepción de los problemas arriba señalados que realizó un lector-escritor del texto celestinesco.

Considero que los dos elementos apuntados (las estrategias de seducción y el asunto del honor) dan luz sobre la concepción ideológica del texto de Rojas, 
en tanto que la ambigüedad implícita en el concepto del honor que maneja Melibea le permite al autor distanciarse de la concepción de un personaje monológico y afirmar un actante complejo que se mueve, gracias a sus propias motivaciones, en el desarrollo de la acción dramática. Comienzo con el análisis del enfrentamiento entre las conciencias de Celestina y Melibea para determinar el papel y el lugar que el concepto medieval del honor tiene en las argumentaciones y cómo es asumido y transgredido por ambos actantes. Posteriormente estudio la lectura que de esta problemática realiza de Silva, con el objetivo de distinguir el nivel de distanciamiento de la concepción ideológica de la Celestina original.

Analizo el tema del honor y su relación con el proyecto ideológico de Fernando de Rojas en los actos IV y $\mathrm{X}^{1}$ y, luego, estudio las estrategias de seducción de Celestina para con Melibea y las respuestas de ésta última en relación con el problema del honor; después comparo la construcción del honor y la seducción que efectúa Rojas con las que realiza de $\operatorname{Silva}^{2} \mathrm{y}$, finalmente diferencio la propuesta ideológica de la Segunda Celestina para observar su alejamiento respecto del texto de la Tragicomedia.

Mis hipótesis son: (a) en las estrategias de seducción de Celestina y el proceso dialógico que desatan entre Melibea y la alcahueta, se manifiesta Melibea como una autoconciencia distanciada de los valores medievales del honor y la fama; (b) el honor de Melibea no resulta de su inscripción en estos valores, sino en su asunción como un sujeto autoconsciente autónomo; (c) en la recepción del texto celestinesco realizada en la lectura-escritura de Feliciano de Silva se presenta un distanciamiento radical de la Tragicomedia, debido a la monologización que de Celestina y de su propuesta ideológica hizo el imitador citado, y (d) esta monologización tiende a aplanar las diferencias ideológicas respecto al epistema medieval construidas por Rojas y a acercar la problemática celestinesca al tópico del honor salvaguardado por la vía del matrimonio.

\section{La seducción de Melibea en Celestina. ${ }^{3}$}

Cuando Celestina visita a Melibea en el acto IV para convencerla de aceptar el amor de Calisto, ya Melibea se había enamorado de éste. ${ }^{4}$ Más que partir de una ignorancia absoluta, el diálogo entre ellas está saturado de supuestos que pronto la alcahueta descubre y a partir de ellos establece sus estrategias, ya no de convencimiento amoroso, sino de aceptación de un complejo sentimiento que ha descubierto en Melibea. De este proceso de la alcahueta el texto muestra al lector un desarrollo, cuyas estrategias de seducción son las siguientes: (a) comparación vejez-juventud, (b) manipulación del discurso religioso, (c) manipulación del tópico cortesano de la enfermedad de amor, (d) adulación de la belleza, (e) alabanza del carpe diem, y (f) manipulación del trabajo celestinesco como un esfuerzo por servir a los demás. ${ }^{5}$ 
Es evidente en Celestina una parodia del amor cortés, puesto que los lectores contemporáneos de Rojas "debían darse cuenta en seguida de que el joven caballero era una figura paródica y, por tanto, ridícula" (Russell 1991, 59). Pero también Melibea se distancia de las reglas del amor cortés al permitir las declaraciones de Calisto y provocar la continuación de la relación.

Desde la primera unidad del diálogo está presente el distanciamiento apuntado, ya que por un lado Calisto introduce en forma abrupta sus intenciones y Melibea da pie a las declaraciones del pretendiente:

Calisto: En esto veo, Melibea, la grandeza de Dios.

Melibea: ¿En qué, Calisto? $(C, 85)$.

Posteriormente, se observa en ella el deseo de conocer las apreciaciones de Calisto y jugar con él manipulando los conceptos de "premio" y "galardón" (“¿Por gran premio tienes éste, Calisto?”; “Pues, aún más ygual galardón te daré yo, si perseveras!"[87]) para hacerle suponer al enamorado que la va a conquistar, cuando lo que en realidad espera es la ingenua suposición de Calisto y su declaración de " $\mathrm{j} \mathrm{O}$ bienaventuradas orejas mías que indignamente tan gran palabra avéys oýdo!" [87] para ridiculizarlo haciéndole ver su gran equivocación. Sin embargo, lo que queda claro es la gran habilidad retórica de Melibea y su audacia para manejar la situación. Luego, observando el peligro en el que ha puesto su honor al no haber cortado desde el principio las declaraciones de Calisto y, por el contrario, haber jugado con él, procura seguir la norma al hacer una defensa del honor: "[...] tu loco atrevimiento, y el intento de tus palabras [Calisto] ha seýdo como de ingenio de tal hombre como tú aver de salir para se perder en la virtud de tal mujer como yo" [87].

En este discurso de Melibea siempre oculta algo, ella nunca dice lo que verdaderamente piensa. Confunde a Calisto porque quiere que el enamorado se declare y, cuando lo hace, Melibea queda satisfecha en su vanidad. Luego de probarle a Calisto su superioridad discursiva, toma la palabra para volver al ocultamiento: se propone como ofendida en consonancia con los valores medievales del honor. Con esto se sujeta a los códigos sociales.

Esta defensa de honor resulta poco convincente "pues para serlo debería haber terminado la conversación al darse cuenta de las intenciones de Calisto, en lugar de coquetear con preguntas y promesas" (Lacarra 1989, 15). Por el contrario, se presenta una Melibea inteligente, conocedora de las reglas del amor cortés y manipuladora de la situación. Si Calisto se ha planteado como egoísta, transgresor de las normas del amor cortés, pues no se ha declarado vasallo ni paciente adorador, sino pretendiente apresurado en espera de una pronta respuesta, Melibea ha mostrado que no es una doncella ingenua. 
Considero, entonces, que el inicio de la Tragicomedia da tres claves de lectura que van a mantenerse como una constante a lo largo del texto. Primero, se presentan los personajes dotados de una autonomía de conciencia mediante la cual se distancian de la presencia de la voz autoral. Segundo, el concepto medieval del honor se transgrede, puesto que Melibea y Celestina no entienden el honor como la "fama" medieval, aunque en un nivel aparencial lo presenten así, como estrategia para no ser excluidas de los espacios sociales donde viven. $Y$ por último, existe en el texto de Rojas una multiplicidad de planos, lo que genera conciencia en el lector de que se mueven otros significados distintos a los que se perciben en un momento dado. Entre lo que dicen los personajes y lo que no dicen, se ocultan supuestos, se dicen las ideas a medias, se juega con el sentido de frases, etc., conviertiendo el texto en un rico entramado de significaciones. Este dinamismo de los planos expresivos es muy importante en la relación de Celestina y Melibea, puesto que sus diálogos siempre van a ocultar lo que ellas verdaderamente piensan y sienten, motivaciones ocultas que son, desde mi punto de vista, las que resuelven la acción dramática en los derroteros que Rojas propuso: una ruptura con el epistema imperante en la Edad Media. Este enfrentamiento, que incluye la transgresión del valor del honor, constituye el proyecto ideológico de Fernando de Rojas.

\section{La seducción de Melibea, acto IV.}

En el acto IV Celestina visita la casa de Pleberio y a pesar del recuerdo que le construye Lucrecia a Alisa, "no sé cómo no tienes memoria de la que empicotaron por hechizera, que vendía las moças a los abades y descasava mil casados" (152), la madre de Melibea, debido a la poca atención que pone a la visita por la enfermedad de su hermana," decide dejar a su hija con la alcahueta, presentándosela antes como "esta mujer honrrada" (153). Hay un hecho que me parece fundamental para explicar el comportamiento de Alisa: Celestina era su vecina; es por esta situación que la esposa de Pleberio confía en que nada le va a pasar a su hija.

Una vez solas, Celestina empieza un proceso de adulación en el cual contrapone los dolores de la vejez con las virtudes de la juventud, así como equipara su propia vejez con su pobreza para ganarse la simpatía y la conmiseración de la doncella. En el primer parlamento que dirige a Melibea se aprovecha del tópico de la juventud para introducir sus propósitos de seducción, puesto que le habla de este período como el "tiempo en que más plazeres y mayores deleytes se alcançarán" (154), elemento del carpe diem que será profusamente explotado por Celestina en la continuación de su proceso de seducción.

En los tres períodos dramáticos que conforman el diálogo entre Celestina y Melibea en el acto IV ${ }^{8}$ la forma de tratamiento que emplea Melibea desde su primera intervención es "madre," incluso lo sigue haciendo después de 
que reconoce a Celestina y luego de que se le pasa el enfado por la propuesta de la alcahueta. El uso de este apelativo forma parte del complejo juego de relaciones del texto y de la necesidad de los otros personajes de subordinarse a una imposible función maternal de Celestina, para lograr sus objetivos. ${ }^{9}$

En el caso del proceso de seducción que analizo, tiene que ver con la estrategia de Melibea de establecer una relación de cercanía, obviando el conocimiento previo que tenía del personaje, para conseguir un fin: alcanzar el amor de Calisto. Melibea necesita alguien en quien confiar para confesarse y dar cabida y aceptación a un sentimiento amoroso que desde el primer diálogo con Calisto experimenta. Celestina es el medio que se le presenta para tener información del amante y dar gestos de correspondencia, aunque, por supuesto, debe proceder con la cautela que le imponen los códigos de su fama y el honor de su elevado nivel social.

Después de que Melibea recuerda que hace dos años no ve a Celestina, ésta última vuelve a la comparación de la vejez con la juventud, para insistir en que su vida ya está en una etapa final, mientras que la doncella posee un cuerpo del que debe disfrutar; le dice "goze desta alma pecadora y tú desse cuerpo gracioso" (158), insistiendo en la estrategia del carpe diem.

Fundamental es la manipulación del discurso religioso. Celestina compara a Melibea con una "angélica ymagen," para señalar que no es pecaminoso el disfrute del cuerpo, sino más bien un mandato divino: “ ¿y no sabes que por la divina boca fue dicho, contra aquel infernal tentador, que no de sólo pan biviriemos?" (158). Y una vez que le ha descubierto que es otro el propósito de su visita: la necesidad de ayudar a un enfermo, ${ }^{10}$ equipara la caridad cristiana con el hecho de compartir el cuerpo, y lo propone como un elemento diferenciador entre el ser humano y el animal, aunado a la repetitiva adulación:

El temor perdí mirando, señora, tu beldad, que no puedo creer que embalde pintasse Dios unos gestos más perfetos que otros, más dotados de gracias, más hermosas facciones, sino que hazerlos almazén de virtudes, de misericordia, de compassión, ministros de sus mercedes y dádivas, como a ti. [Y], pues como todos seamos humanos, nascidos para morir, y sea cierto que no se puede dezir nascido el que para sí solo nasció. Porque sería semejante a los brutos animales, en los quales aún ay algunos piadosos. (...) ¿Por qué no daremos parte de nuestras gracias y personas a los próximos? Mayormente quando están embueltos en secretas enfermedades, y tales que, donde está la melezina, salió la causa de la enfermedad. (160-161)

Celestina introduce el caso de Calisto como una enfermedad. Sabido es 
que "la enfermedad de amor fue conocida y descrita por la medicina griega clásica, que transmitida y reelaborada después por la medicina árabe, pasó a formar parte integral de la medicina medieval" (Lacarra Lanz 1999, 20). Este elemento integró, también, los cánones del amor cortés.

Melibea al oír el nombre de Calisto y tener presente los dobles sentidos de compartir la hermosura y disfrutar de la juventud recién escuchados, además de reconocer al enunciador de tales discursos, reacciona violentamente en defensa de su honor llamando a Celestina "alcahueta falsa, hechizera, enemiga de honestidad" (161) y señalándole que ha entendido sus intenciones y no desea perder su fama ni la de su familia:

¿Querrías condenar mi honestidad por dar vida a un loco, dexar a mí triste por alegrar a él, y llevar tú el provecho de mi perdición, el galardón de mi yerro? ¿Perder y destruýr la casa y honrra de mi padre por ganar la de una vieja maldita como tú? ¿Piensas que no tengo sentidas tus pisadas y entendido tu dañado mensaje? (162)

Pero en ningún momento decide Melibea cortar inmediatamente el diálogo y expulsar violentamente a Celestina, sino que, por el contrario, la insta a continuar el diálogo: "Respóndeme, traydora" (162), y en vez de poner una distancia rotunda a la pretendida buscadora de su mal, le comenta que sostuvo una conversación con Calisto y que con él "holgué más de consentir sus necedades que castigar su yerro (...)" (163).

Al notar el enojo de Melibea y al mismo tiempo su deseo de seguir dialogando, Celestina recurre al tópico de la enfermedad de muelas y le solicita la oración de Santa Polonia y el cordón para ayudar a la curación de Calisto. ${ }^{11}$ Melibea necesitaba aparentar su ira para dejar a salvo su honor y Celestina se da cuenta de eso, asimismo comprende que Melibea está muy interesada en Calisto, por ello la estrategia de la alcahueta se orienta ahora a hablar de Calisto pero a partir de su enfermedad. También recurre a otra táctica: victimizarse y señalar que es por su afán humanitario, por su denodado esfuerzo de servir a los demás que corre riesgos: "Que no es otro mi officio sino servir a los semejantes. Desto vivo, y desto me arreo" (165).

Por otra parte, Melibea, dando muestras de una gran estatura intelectual y ubicándose bien en el enfrentamiento, confiesa que sí sabe ante quien está: "Por cierto, tantos y tales loores me han dicho de tus falsas mañas que no sé si crea que pedías oración" (165-166) y con toda responsabilidad continúa su entrevista, a pesar de que le indica " (...) bien sé que ni juramiento ni tormento te bará dezir verdad" (166). Esto se debe a que Melibea ha aceptado la situación, sabe las intenciones de Celestina pero desea someterse a su mediación porque está muy interesada en Calisto. Por ello no le queda más que dejar a un lado su 
estrategia del enojo, ya que ha cumplido con las reglas sociales que le exigían una respuesta bravía, y ahora, en medio de las contradicciones apuntadas (saber quién es Celestina, lo que pretende y la posibilidad de perder el honor) cae en otra, decide olvidar la supuesta ofensa de Celestina y perdonarla ${ }^{12}$ con el propósito de lograr la intermediación:

Pero pues todo viene de buena parte, de lo passado aya perdón; que en alguna manera es aliviado mi coraçón, viendo que es obra pía y santa sanar los apassionados y enfermos. (166)

Desde el inicio del acto Melibea ha estado interesada en conocer las intenciones de Celestina y cuando se entera del objetivo de su visita, ese interés aumenta y una vez hecha la convencional defensa del honor, cumpliendo así sus deberes con "la sanción de la sociedad" (Lida de Malkiel 1970, 406), la doncella decide seguirle el juego a Celestina y aceptar el contrato de verosimilitud de la supuesta enfermedad. Celestina, astutamente, se da cuenta del pacto entre lo que se puede decir y lo que se oculta e insiste en mencionar elementos sobre Calisto que sabe son del mayor interés de Melibea. Debido a esto lo idealiza recurriendo a comparaciones con grandes héroes de la antigüedad,,$^{13}$ mencionando su edad, aludiendo a sus falsos dotes de cantante y procurando darle celos: "Ninguna mujer le ve que no alabe a Dios que assí le pintó; pues si le habla acaso, no es más señora de sí de lo que él ordena" (168).

Melibea ha efectuado una estrategia de sustitución, no puede aceptar que está interesada sexualmente en un hombre, pero sí que está preocupada por un enfermo. En vez de una atención de galanteo afirma ante Celestina un espíritu caritativo y bondadoso, acordes con los valores cristianos de la época: ésta es la máscara que necesita para cumplir sus obligaciones sociales. Tanto ella como Celestina entienden la necesidad de la sustitución y ven cumplidos sus respectivos intereses: Celestina logró el cordón y otra visita, Melibea tener información sobre el amor de Calisto y demostrarle a la alcahueta su gran interés de que le sirva también como intermediaria.

Ante tanto elogio por parte de Celestina, Melibea se lamenta de su reacción violenta contra la alcahueta y bajo la máscara ganada descubre su interés para con el enfermo solicitando una segunda visita, pero ahora sí ocultándola de su familia :

En pago de tu buen sufrimiento quiero complir tu demanda y darte luego mi cordón. Y porque para screvir la oración no avrá tiempo sin que venga mi madre, si esto no bastare, ven mañana por ella muy secretamente. $(C, 168)$

Lucrecia reconoce el doble discurso y reacciona sorprendida “¡más le querrá 
dar que lo dicho!" y Melibea advierte a Celestina que "no le des parte de lo que passó a esse cavallero" (168), queriendo seguir con el ocultamiento, sabiendo que la intermediaria irá pronto a dar informe de su misión.

Celestina está por marcharse cuando Melibea le reafirma su interés por Calisto: "Más haré por tu doliente" (169) y la alcahueta se despide volviendo a su discurso religioso, esta vez sobre la naturalidad de las relaciones amorosas: "cada día ay hombres penados por mujeres y mujeres por hombres, y esto obra la natura y la natura ordenóla Dios, y Dios no hizo cosa mala" (170). Celestina se retira sabiendo que Melibea está enamorada de Calisto pero se resiste a confesarlo, y Melibea ha logrado comunicar su sentimiento.

\section{La seducción de Melibea, acto $X$.}

Una prueba de la autonomía de conciencia de Melibea es que ella en el acto IX envía a Lucrecia por Celestina. La criada va a la casa de la vieja y allá le dice: "(...) te ruega mi señora sea de ti visitada y muy presto, porque se siente muy fatigada de desmayos y de dolor del coraçón" (237). En el acto X está la doncella muy dolida de su mal de amor y, llena de celos, se pregunta si Calisto "desconfiando de mi buena respuesta aya puesto sus ojos en amor de otra?" (238).

Melibea ha decidido romper con el entorno social que le requería el cuidado de su honra. Considera que no debe ocultar su "terrible passión" (238) y se lamenta de la situación de la mujer en su época: “¿por qué no fue también a las hembras concedido poder descobrir su congoxoso y ardiente amor como a los varones?" (239). ${ }^{14}$

Pero no puede aceptar en forma evidente ante Celestina su cambio de actitud y decide retomar el juego de apariencias mediante la enfermedad de amor y le afirma sentir que "me comen este coraçón serpientes dentro de mi cuerpo" (239). Melibea necesita a Celestina porque la vieja traduce en su discurso los deseos de los personajes, es una especialista del engaño que saca a luz las intenciones y los secretos de los demás. Melibea "la manda a llamar para que la vieja pronuncie lo indecible: lo que Melibea necesita es que su deseo cobre existencia al ser dicho" (Alcalá Galán 1996, 47). Melibea no se atreve a enunciar la decisión que ya ha interiorizado. Para hacerlo requiere de la intermediación de la alcahueta, quien le proporcionará el paso de la subjetividad hacia la exteriorización de su sentimiento, primero a Celestina misma, luego a Lucrecia y posteriormente a Calisto.

Celestina, desde el acto IV, conocía el sentimiento de Melibea y su reticencia a aceptarlo y a someterse a las consecuencias del mismo. Sin embargo, estaba ofendida por los insultos que le había proferido la doncella cuando llena de orgullo fingía defender su honor; así que la alcahueta decide vengarse: "Bien 
está; assí lo quería yo. Tú me pagarás, doña loca, la sobra de tu yra, " y ahora le sigue el juego: “QQuieres que adevine la causa?” (239). Melibea claudica y vedadamente le confiesa no buscar el enfrentamiento; le expresa su necesidad de que le diga simplemente que se ha enamorado de Calisto, por ello le confiesa rendida "veo mi coraçón entre tus manos hecho pedaços" (240).

Sin embargo, Melibea persiste aún con la retórica de la sustitución de su amor por la citada enfermedad y Celestina acepta el pacto porque quiere que Melibea se venza aún más y confiese con claridad su pena, así que la increpa: "cumple que al médico como al confesor se hable toda verdad abiertamente" (240). Melibea se oculta de nuevo para que sea la alcahueta quien descubra la causa de sus malestares. Desde el acto IV, existe, siguiendo a Lotman, un "mecanismo lúdico" que manifiesta la existencia de otros significados ocultos en los discursos de los personajes. ${ }^{15}$

Considero que este mecanismo es el que funciona en la seducción de Melibea, el cual nunca es unidireccional sino que, por el contrario, es un proceso doble, uno que dirige tanto Celestina a Melibea como Melibea a Celestina. Cada uno de los personajes es portador de intereses particulares y su conducta va dirigida a conseguir sus aspiraciones, por lo que los procesos de convencimiento de Celestina tienen que tener en cuenta los intereses de Melibea, así que la alcahueta queriendo resarcir su orgullo herido le sigue el juego de la enfermedad de amor y se presenta como un experto médico.

En el juego de interrelaciones quedan en superficie los significados de la enfermedad de amor: la alteración de Melibea, sus síntomas, el lugar donde más dolor siente: "Mi mal es de coraçón, la ysquierda teta es su aposentamiento; tiende sus rayos a todas partes. Lo segundo, es nuevamente nascido en mi cuerpo, que no pensé jamás que podía dolor privar el seso como éste haze; túrbame la cara; quítame el comer; no puedo dormir; ningún género de risa querría ver" (241). En otro plano de sentido distinto a éste está la preocupación forzada por su honra, aunque sabe que lo que busca en Celestina va a hacerla perder este valor. No obstante, ella ha determinado aceptar su amor hacia Calisto y tal defensa no es más que parte del juego de apariencias que debe sostener. Así que se hace evidente la ambigüedad del discurso de Melibea cuando le pide la cura a Celestina pero le advierte que "mi honrra no dañes con tus palabras" (241) y en su próxima intervención (refiriéndose al remedio) reitera "te pido le muestres, quedando libre mi honrra" (242).

Junto con estos significados, su enfermedad y su interés por la honra, está el más importante: su aceptación de estar enamorada de Calisto. Significado que en su décimo parlamento se manifiesta ya no como un supuesto, sino como un elemento que sale a la superficie terminando con los ocultamientos y el juego de supuestos: 
Melibea. ¡ O cómo me muero con tu dilatar! $\mathrm{Di}$, por Dios, lo que quisieres, haz lo que supieres, que no podrá ser tu remedio tan áspero que yguale con mi pena y tormento. Agora toque en mi honrra, agora dañe mi fama, agora lastime mi cuerpo, aunque sea romper mis carnes para sacar mi dolorido coraçón, te doy mi fe ser segura, y si siento alivio, bien galardonada. (242)

Celestina no ha querido mencionar la causa del "mal" de Melibea porque la alcahueta se ha visto maltratada por el enojo de Melibea en el acto IV, por lo que pacientemente da rodeos para que sea Melibea la que tenga que confesarla. Ya Celestina sabe que hace rato Melibea está en sus manos (la doncella incluso la llama "amada maestra" (242) y ahora la vieja juega con ella: "Tu llaga es grande, tiene necessidad de áspera cura" (243), vuelve al tema de la enfermedad y no habla claro, aunque menciona el nombre de Calisto pero no haciendo alusión al remedio de Melibea sino al enfermo que han ayudado, con el propósito de exasperar a Melibea, la cual no termina de enunciar su amor. Así que Celestina concluye que padece de "amor dulce" y que su remedio se llama Calisto. Melibea se desmaya y Celestina se asusta, pero Melibea deja de una vez por todas de fingir y le confiesa: "Quebróse mi honestidad (...) lo que tú tan abiertamente conosces en vano trabajo por te lo encobrir" (245), y ya Melibea, por su propia decisión, se somete completamente a la voluntad de Celestina. Y al hacerlo, se libera, declarando un sentimiento que hacía ya bastante tiempo había aceptado pero que le era difícil enunciar:

¡O mi Calisto y mi señor, mi dulce y suave alegría! Si tu coraçón siente lo que agora el mío, maravillada estoy cómo la absencia te consiente bivir. ¡O mi madre y mi señora, haz de manera como luego le pueda ver, si mi vida quieres! (246)

A partir de este momento Melibea es quien decide sobre su vida. Creo que en este sentido se manifiesta ella como una conciencia autónoma, de acuerdo con Bajtín, ${ }^{16}$ independiente del autor.

Rojas otorgó una conciencia autónoma a sus personajes y una voz propia capaz de analizar el mundo y decidir de acuerdo con sus intereses. Cuando Melibea ha decidido asumir su amor y vivirlo, le dice a Lucrecia: "cativóme el amor de aquel cavallero; ruégote por Dios se cubra con secreto sello porque yo goze de tan suave amor" (247). Con esto está destacando su autonomía, tanto de la sociedad que la va a juzgar mal como de sus padres, a quienes quiere. ${ }^{17} \mathrm{La}$ solicitud del secreto de la relación tiene que ver con su decisión, ya que no quiere que nadie interfiera con su voluntad.

El proceso de seducción de Melibea, entonces, no se debe leer como 
una relación vertical en la que la vieja seduce a una inocente doncella a la cual le destruye su capacidad intelectual gracias a que tenía de aliado al demonio. Tampoco pienso que Rojas se propusiera en estos dos actos "desarrollar la tentación y caída de Melibea" (Ayerbe-Chaux 1978, 4). ${ }^{18}$

Por el contrario, se presenta el proceso dialógico de Melibea y Celestina en el cual ambas defienden sus intereses a partir de una conciencia autónoma y una evaluación racional de la realidad en la que viven. El honor para Celestina consiste en su profesionalismo, en la destreza con la que asume su oficio de alcahueta y mediadora. Para Melibea, el honor se desplaza de la protección de la fama para convertirse en la defensa de su conciencia autónoma como sujeto individual. Ella es un personaje que mantiene, en términos de Bajtín, "un punto de vista particular sobre el mundo y sobre sí mismo, como una posición plena de sentido" $(1985,71)$. Esta libertad de elección es la que le permite construir un ideal del amor en tanto proyecto de vida y de muerte. Esto explica su decisión de amar por sí misma, su idealización del ridículo Calisto, su rebeldía y enfrentamiento con los valores sociales y con sus padres, así como su rechazo del matrimonio en cuanto institución:

Calisto es mi ánima, mi vida, mi señor, en quien yo tengo toda mi sperança; conozco dél que no bivo engañada. Pues él me ama, ¿con qué otra cosa le puedo pagar? Todas las debdas del mundo reciben compensación en diverso género; el amor no admite sino sólo amor por paga; en pensar en él me alegro, en verle me gozo; en oýrle me glorifico; haga y ordene de mí a su voluntad. Si passar quisiere la mar, con él yré; si rodear el mundo, lléveme consigo; si venderme en tierra de enemigos, no rehuyré su querer; déxenme mis padres gozar dél si ellos quieren gozar de mí. No piensen en estas vanidades ni en estos casamientos, que más vale ser buena amiga que mala casada; déxenme gozar mi mocedad alegre si quieren gozar su vejez cansada; si no, presto podrán aparejar mi perdición y su sepultura. (304)

Desde esta conciencia de libertad Melibea escoge el amor como proyecto vital. Para ella es lo más importante de su existencia y por él desecha todo lo demás. Su autonomía como sujeto ${ }^{19}$ la libera de sus compromisos sociales ${ }^{20}$ y en sus enunciados construye una diferente dimensión del honor: en vez de la fama social reivindica la individualidad de una mujer que asume su existencia bajo responsabilidad propia.

El amor de Melibea es muy particular porque no se trata de una pasión ciega, sino de una voluntad libremente elegida y deliberadamente idealizada. Para ella Calisto no es el hombre ridículo de la realidad sino el héroe de sus lecturas, el "más acabado hombre que en gracias nació" (333). Este amor es un 
acto de conciencia personal asumido a contracorriente de las normas sociales de la época, ${ }^{21}$ hecho que manifiesta una profunda individualidad, la cual la hace escoger la muerte como salida. Su muerte es una decisión, una afirmación de su autoconciencia como sujeto, la manifestación de su voluntad de poder. ${ }^{22}$

La muerte de Melibea, entonces, representa el triunfo de su voluntad..$^{23}$ Así como se había enfadado por el criterio que sus padres tenían de ella y le dice a Lucrecia que les interrumpa "si no quieres que vaya yo dando bozes como loca, según estoy enojada del concepto engañoso que tienen de mi ignorancia" (306), igualmente escoge ella sola su muerte: “(...) algún alivio siento en ver que tan presto seremos juntos yo y aquel mi querido y amado Calisto. Quiero cerrar la puerta, por que ninguno suba a me estorvar mi muerte (331). El honor de Melibea no se encuentra, entonces, en su virginidad ni en su fama, sino en la rebeldía de la autoconciencia de un sujeto libre y hacedor de su propio destino. Su muerte es el resultado de su afirmación como sujeto, determinación de una autoconciencia que revela el tránsito del epistema medieval al renacentista, ${ }^{24}$ en el cual la categoría de individualidad cobra una importancia trascendental.

\section{La seducción de Polandria en la Segunda Celestina.}

La Segunda Celestina de Feliciano de Silva intenta seguir el texto de Rojas en cuanto presenta un joven noble, Felides, que se enamora de una doncella encerrada, Polandria, hija de Paltrana, señora de la alta sociedad. También existen dos criados, Sigeril, a quien Felides le confiesa sus penas de amor, tal como lo hace Calisto con Sempronio, y Pandulfo, un rufián mentiroso y cobarde que dista mucho de la compleja caracterización del Pármeno de original.

En cuanto a los acontecimientos, Felides le encomienda a Pandulfo que trate de conquistar el amor de Quincia, criada de Paltrana, con la finalidad de tener algún acceso a la casa de su enamorada. Pero cuando se entera de la resurrección de Celestina, recurre a ella y le encarga la conquista de Polandria. La alcahueta, luego de varios rodeos, acepta ser intermediaria. Entre estos hechos de Silva mezcla muchos acontecimientos más que desvían la trama principal, por ejemplo, los amores de Acays y Filinides. ${ }^{25}$

Siguiendo el texto de Rojas, antes de que Celestina hable con Polandria ésta ya está enamorada de Felides. En la cena XVIII expresa:

¡Ay de mí!, que no de balde se dize: lo que ojos no veen, que el coraçón no dessea; si yo no viera la carta de Felides haviendo visto su hermosura, no deesseara el coraçón lo que la razón aborrece. ¡ $\mathrm{Oh}$, amor, y cuán contrario de razón te hallo, cuán amigo del desseo te veo, cuán contrario te honesticidad te miro, cuán enemigo de honra te entiendo! ${ }^{26}$ 
En la cena XX Celestina visita la casa de Paltrana, presentándose como reformada de sus antiguas costumbres y como una religiosa conservadora, con la finalidad de tener acceso más fácil a las residencias y a los lugares donde anteriormente no era bien recibida por su oficio. Cuando llega, Quincia hace recordar el papel de advertidora que cumple Lucrecia en el texto de Rojas ${ }^{27}$ : " ¡Válala el diablo la vieja! Señora, mala muerte me tome si Celestina, la que resucitó, no está allí" (SC, 311). Pero de Silva se vale del interés que en los personajes tiene el otro mundo y Polandria le pide a su madre que la haga pasar para tener alguna noticia del más allá.

La situación se simplifica en este caso, puesto que Paltrana hace pasar a Celestina y con toda confianza, le dice "comadre honrada, para bien sea tu venida, que Dios sabe el gozo que en esta casa de tu resurrectión se ha tenido" (SC, 311312). Celestina utiliza el conocimiento que posee de la enfermedad de Paltrana, aspecto que de Silva toma del texto de Rojas, ${ }^{28}$ para justificar su visita:

como no he atrabesado ell umbral de mi casa después que vine a este siglo, hasta que vine aquí; y también, la verdad, porque hablar claro Dios lo dixo, supe de tu enfermedad, y parescióme causa que acrescentava en la obligación de visitarte primero que a otra ninguna señora deste lugar, que, a Dios gracias, tengo hartas, no porque yo lo meresca a Dios, mas por su virtud. $(S C, 312)$

Una de las estrategias de seducción de Celestina es la utilización del discurso religioso, en tanto se presenta como transformada luego de su resurrección. Para introducirse en la casa de Polandria adula la belleza y juventud de Paltrana, le dice: "Assí que, hija, en cuanto tuvieres con qué pagar a Dios las mercedes que te dio con darte ser y hermosura y gracia, y sobre todo hazerte cristiana, no aguardes a la vejez, pues, mi amor, no sabemos el día ni la hora de la muerte, siendo cada día más cierta y más natural hora de morir que no de bivir" (SC, 316).

Celestina pide lumbre y aplica unos masajes a Paltrana, la cual se muestra sorprendida por la supuesta transformación religiosa de Celestina, mientras que la alcahueta emplea el mecanismo de la adulación con Paltrana también aprovecha para elogiar a Polandria: “ $i A y$, gesto de ángel, con qué gracia lo dizes!" (SC, 313) ${ }^{29}$ y a Paltrana: “(...) con su niñez no puede tener mejor barriga y pechos que tienes" (SC, 318). Ésta última, en vez de sospechar algo, queda impresionada por Celestina y la insta a visitarla para que sea ejemplo de religiosidad ante su hija.

Cuando Celestina le da un remedio para su enfermedad de costado, le encomienda a Polandria que, junto con Poncia, lleven a la vieja a pasear al jardín, abriéndole el espacio que necesita Celestina. Una vez en el jardín, Poncia le 
pregunta a Celestina si vio en el otro mundo a Melibea, a lo que la alcahueta responde: "Mi amor, no se pueden dezir essos secretos, bástete saber que fue homicida de sí misma" (SC, 320), señalando su desacuerdo con la forma en que murió el personaje de Rojas. ${ }^{30}$

Queda clara entonces, la perspectiva ideológica del imitador, la cual le hará no solamente abandonar el problema del suicidio, sino dar a la historia un "final feliz" acorde con las instituciones religiosas. Estas referencias al texto de Rojas se presentan con frecuencia en la Segunda Celestina, en un esfuerzo de la imitación por recordar su adscripción al modelo.

Posteriormente Celestina solicita a Poncia que la deje sola con Polandria $\mathrm{y}$, cuando lo consigue, le señala que lo que tiene que comunicarle "yo lo digo por tu provecho" (SC, 323), empleando la estrategia de fingirse servidora de los demás. Además, insiste en el servicio que le va a hacer, porque eso podría costarle la vida "(...) y baste havella perdido una vez por Calisto, sin culpa, no querría perdella otra vez por Felides" (SC, 323), en otra referencia al texto de Rojas. A lo que Polandria le comenta que puede confiarle cualquier secreto y que ella no la delatará.

Con esta mansedumbre por parte de Polandria, Celestina le confiesa el propósito de su visita, en una referencia, otra vez, al texto de Rojas: “(...) que este cavallero anda loco perdido por tus amores, hecho otro Calisto y peor" (SC, 324), a lo que responde Polandria:

A buena fe, tía, que si acabas como has encomençado, que no dexe de pensar que te ha dado dineros aquel loco por tercera; mas con las palabras que me dixiste me quiero asossegar hasta acabarte de oír. $(S C, 324)$

En el diálogo no hay supuestos ni ocultamientos, no existen planos lúdicos. La conversación es llana y Polandria no polemiza con Celestina, ni la alcahueta parece dotada de artes de convencimiento. Son personajes planos, "tipos" que obedecen a la conciencia del autor y siguen líneas para proponer la secuencia planeada de antemano por de Silva. Si bien aparecen las estrategias de la manipulación del discurso religioso, la adulación de la belleza, el tópico de la enfermedad de amor y la estrategia de presentarse como servidora de los demás, éstas son débiles y no tienen la funcionalidad de presentar el dinamismo de caracteres, tal como las utiliza Rojas.

Polandria en realidad no parece alterada como dice Celestina (" $i Q u i e ́ n$ te vio tan mansa!, ¡quién te vee agora tan çahareña y alterada! $(S C, 324)$, no arguye razones ni enfrenta a Celestina. Entonces, la vieja, sigue con su proceso de convencimiento presentándole a Felides con la enfermedad de amor: "(...) 
por tu causa ni come, ni duerme, ni vela, según está adormido en pensarte, ni oye, y por cierto, que está tal, que pienso que ya ni ve, ni palpa" (SC, 324), ${ }^{31}$ pero el tópico de la enfermedad de amor no tiene los contrasentidos ni se explota con la riqueza con que lo hace Rojas. Posteriormente Celestina le dice a Polandria que las mujeres no son de piedra sino de "la natural condición de las mugeres, pidadosa" $(S C, 325)$ y en un esfuerzo por imitar el ardid de Celestina con el dolor de muelas de Calisto, la Celestina de Feliciano de Silva termina diciéndole a Polandria que se guarde, orientando a su seducida a desconfiar de Felides. Con clara distancia del texto de Rojas, Celestina no busca en realidad transgredir la honra de Polandria y el texto se cuida de ello:

Que te guardes y santigües con la mano derecha quiero dezir, y si hasta aquí le has dado alguna limosna de favor con la izquierda, que no puede ser menos en tales burlas, que no lo sepa la tu derecha, pues sabes que la honra de las mugeres no está en más de la común opinión. (SC, 325)

Entonces Polandria le confiesa que Felides le envió una carta y Celestina le dice que más sabe ella, puesto que conoce que no lo quiere mal, a lo que agrega elementos que procuran idealizar a Felides ("un Alexandre en franqueza y un Héctor en fortaleza," SC, 326) en otra referencia al texto de Rojas. ${ }^{32}$ Polandria, sin que medie ningún enfrentamiento discursivo para salvaguardar una posible pérdida del honor y sin que haya ninguna orgullosa insistencia en no querer someterse al dominio de la alcahueta (como lo hace Melibea), sonríe para confesarle a Celestina:

Pardiós, madre, no le quiero mal, ¿para qué es sino dezir la verdad? Mas assí lo quiero bien con que no me quiera mal. (SC, 326-327)

Celestina se despide de Polandria y ésta última, igual que Melibea, le suplica que "no digas nada a aquel cavallero desto que ha passado" (SC, 327).

En la cena XXVI se da el proceso de la respuesta de Polandria a la petición de Celestina. A diferencia del texto de Rojas, no es Polandria quien ha llamado a la alcahueta. Ella llega por sus propios intereses con la excusa de saber el estado de salud de Paltrana. Pero antes de que sea anunciada por Quincia, es fundamental el diálogo entre Poncia y Polandria. La criada, quien es realmente la que asume el papel protagónico, ha pensado en el problema de Polandria, después de que la doncella le ha confiado su amor en la cena XXIV, y le propone:

temo tu enfermedad, y no querría que la pena de aquel cavallero junto con el amor que le tienes diessen lugar, con el tiempo, a publicar alguna cosa con que tu fama y honra padeciesse sin culpa, por donde la gloria de tu fortaleza en lo secreto no sirviesse más de para contigo. 
Y para esto he pensado que sería bien, si alguna cosa de su parte te dixessen, pedille que se case contigo secretamente, porque público pienso que tu madre no querrá, porque aunque él es tan rico y de muy buen linaje, ya sabes que tu mayorazgo que no puedes heredallo casándote fuera de tu linaje. Mas yo por mejor tendría la pérdida de la hazienda que la de la honra. (SC, 389)

Con esta introducción de la cena quedan ya claros dos aspectos: (1) por un lado no es Polandria un personaje que piense por sí misma, mucho menos un actante con autoconciencia autónoma, tal como Melibea. Y (2) por el otro lado, queda ya planteada la perspectiva ideológica de Feliciano de Silva: no es posible pensar las relaciones amorosas fuera del matrimonio, y de sostener esto se encarga Poncia, quien asume el papel protagónico y es la portavoz de la propuesta ideológica del autor. Para cerrar el monologismo del texto, dice Polandria a la iniciativa de su criada: "Yo estoy en lo que dizes, y así lo entiendo hazer" (SC, 390).

En adelante, Celestina se reduce a un personaje de escasa presencia y estatura; inmersa en un monologismo subrayado, en realidad se puede pensar más en la seducción de Poncia hacia Polandria y Celestina (la criada asume el papel protagónico y se encarga de expresar el conservadurismo de Silva).

Así que ya está todo resuelto, lo que falta de la cena y del texto es desarrollar los deseos de Poncia. Cuando llega Celestina, Polandria, siguiendo a su criada, increpa a Celestina: "Allá, allá a otras baxas donzellas de linaje y de saber, buena muger, ve tú con esas palabras disfraçadas en lisonjas e hiproquesía, que no a mí; que te las entiendo" (SC, 395).

Pero Polandria no piensa en realidad, sino solo sigue los consejos de Poncia y procura amedrentar a Celestina con la actitud de una doncella que se ve en riesgo de perder su honor. Celestina se refugia en la estrategia de la servidora fiel y honesta: "tú me pagas bien con deshonra lo que yo por tu honra trabajo" $(S C, 396)$ y en la de la víctima inocente, haciendo empleo del discurso religioso pero asumido sin ambigüedades: "honestamente trato, de castidad me precio, no me embiaron del otro mundo a tales liviandades" (SC, 397). Si Celestina ha presentado como una estrategia de seducción su discurso religioso, es decir que lo plantea como una trampa para hacer caer a sus víctimas, realmente es ella quien cae en él y así el final del texto lo confirma, cuando la última referencia a ella es que se va a misa ${ }^{33}$ y que será la encargada de hablar con Paltrana para el matrimonio de Polandria. ${ }^{34}$ Celestina deviene un personaje "cristiano" tan distante de la "hechizera, astuta, sagaz en quantas maldades hay" (103) que Sempronio le describe a Calisto, que es sustituida por una criada quien sólo piensa en el honor y el matrimonio.

Esta Celestina resucitada se presenta en diálogos y apartes fingiendo 
ambigüedad y dobles intenciones; por ejemplo, cuando le informa a Felides del resultado de su entrevista con Polandria le dice "(...) me aproveché de mi saber (...) mas desnudéme de verdad por vestirlla de lisonja, para ganalle la boca" (SC, 332-333). No obstante, no logra nada con sus dobles intenciones y no convence tampoco a Polandria. El texto se encarga de irla reduciendo y termina desapareciendo de la acción. Su destitución obedece a la intención del autor de poner en evidencia el triunfo de las ideas de Poncia.

Ante los gritos de Celestina por los cuestionamientos de Polandria, llega Poncia a ayudar a su ama y le dice a la vieja que se explique en caso de que Polandria se haya equivocado, ante lo que la alcahueta señala que su intención era proponer que Felides hablara de matrimonio:

digo y torno a dezir que es bien que sepa aquel cavallero, que si él se ha de casar contigo, que hable en ello comigo o con otra persona, y que de otra suerte que no ande haziendo liviandades. $(S C, 399)$

Poncia interviene y replica a Celestina que le parece lo más sano el consejo ya que "querría a mi señora Polandria más vella casada con este cavallero que con el emperador" (SC, 400). Luego Celestina se ofrece para hacer venir a Felides a que le proponga matrimonio a Polandria y es tanta la disminución de Polandria que sugiere que sea Poncia quien le hable al enamorado. Ante la ida de Celestina, Polandria le pregunta a su criada: "¿Paréscete, Poncia, que lo supe bien hazer?" (SC, 403). Ocurre, entonces, la seducción tanto de Celestina como de Polandria por Poncia, ya que la criada resulta más inteligente y diestra que la alcahueta y es la que hace predominar su voluntad. ${ }^{35}$

Lo que ocurre después es totalmente previsible: Celestina concierta la cita con Felides, Poncia lo convence de que se case en secreto con Polandria, lo que él acepta gustoso. Poncia se encarga de cerrar la unión:

Pues los que Dios y yo hemos ayuntado no los apartará Sigeril, que comigo será testigo. Y agora que, señor, has dicho la palabra de seguridad que te demandé, di la segunda désta y primera de desposado. $(S C, 447)$

Polandria, por su parte, no se muestra feliz de haber obtenido su amor, sino de haber defendido su honra:

para con mayor gloria ganar la vitoria de mi honestidad en la cruel guerra de la sinrazón de amor, resistida con la defensa de la mayor razón del amor de mi virtud, con aquella vergüença que más a mí que a los estraños devía; porque dellos puedo huir o esconderme, lo que de mí no puedo, pues contino donde fuera fuera comigo la 
vergüença de haver faltado a mí, a la obligación de aquella honra y fama que mis passados con tantos trabajos me dexaron, con el autoridad de su linaje sostenida en los trabajos, premios de la honra, que con descanso a ninguno es otorgada. (SC, 447-448)

Al final del texto, Poncia se casa también en secreto con Sigeril, bajo el padrinazgo de Felides, pero no tiene relaciones sexuales con su marido hasta después de celebrar la boda en la iglesia. Antes bien, Poncia le reprocha a Polandria haberse entregado a Felides antes de velarse. Celestina se va a misa y Felides le promete a Polandria que irá a pedir su mano ante Paltrana para casarse por la iglesia.

Con esto el texto cierra cualquier rebeldía contra la sociedad. No hay personajes que posean una autonomía de conciencia, excepto Poncia quien representa la ideología medieval y es la portavoz del epistema de la Edad Me$\mathrm{dia}^{36}$ la cual se impone ante los demás personajes y ante todas las situaciones. El horizonte de expectativas ${ }^{37}$ de Feliciano de Silva le movió a leer y a reescribir Celestina obviando de ella los aspectos que se salían del ideologema medieval y resolviendo la ambigüedad del texto. Ante una Melibea con una conciencia propia que rompe las normas de la sociedad y ni siquiera menciona el matrimonio como opción, de Silva instaura una Polandria que no piensa por sí misma y que antes que otra cosa se obsesiona con el triunfo de su honra. Por otra parte, en vez de una Celestina astuta y complejamente estructurada, de Silva propone una Celestina desdibujada que es derrotada por una criada inmersa en los valores medievales, que defiende el honor y el matrimonio como los fines últimos de la existencia. En fin, frente a personajes complejos y situaciones trágicas, de Silva simplifica en exceso los personajes para imponer un "final feliz" donde triunfa el epistema medieval. En manos de Feliciano de Silva el texto celestinesco pasó de su inmenso carácter dialógico a una conservadora monologización.

\section{Conclusiones.}

Las estrategias de seducción de Celestina para con Melibea en la Celestina de Fernando de Rojas son un entramado de argumentaciones que revelan el dinamismo de un actante complejo en busca de hacer cumplir sus intereses. Pero, también, muestran las respuestas que otro carácter igualmente complejo $\mathrm{da}$ al proceso, resultando un texto donde dos autoconciencias se enfrentan con intereses bien definidos y buscan cada una satisfacer sus respectivos intereses. Por una parte, Celestina quiere conquistar a Melibea para Calisto, y por la otra Melibea desea revelarle su amor a la alcahueta para hacer saber de un sentimiento que ya era parte de ella.

En este proceso, el concepto del honor tiene dos facetas: por un lado es un código social que se debía respetar, por ello tanto Melibea como Celestina procuran respetarlo discursivamente, pero la joven termina transgrediéndolo. 
Por el otro lado, para Celestina su honor tiene que ver con su éxito profesional, mientras que para Melibea no corresponde con la categoría de la "fama" medieval, sino con la libertad de su autoconciencia para decidir su vida. Es por esto que en el texto de Rojas esta noción no tiene relación con su simbología medieval. Tanto Celestina como Melibea son actantes dotados de una autoconciencia que los hace actuar siguiendo sus propias motivaciones, alejados de una voz autoral que los manipule.

En la Segunda Celestina de Feliciano de Silva las estrategias de seducción se reducen tanto cuantitativa como significativamente. Aparecen las estrategias de la adulación de la belleza, la autopresentación de Celestina como servidora de los demás, la presencia del discurso religioso y la presentación de la enfermedad de amor, pero en el texto se pierde el dinamismo del proceso dialógico que se estructura en Celestina. Esto se debe, según mi perspectiva, a la monologización que lleva a cabo de Silva de los personajes de Rojas, situación que se explica por el distanciamiento de la Segunda Celestina del proyecto ideológico de Rojas.

Celestina se aleja de los cánones institucionales medievales: religiosos, sobre el honor y el matrimonio, y, en general, sobre la valoración de la vida. Su propuesta es sumamente ambigua y deja a los personajes la opción de buscar sus propias respuestas a la vida humana. Celestina la encuentra en su profesión y Melibea en el suicidio al escoger no vivir sin Calisto.

La Segunda Celestina procura resolver esa ambigüedad y retomar los cánones institucionales medievales como garantes de la verdad y la seguridad. Es por ello que en esta obra Segunda Celestina no se presenta ni el suicidio ni la muerte como opciones de los actantes, sino el matrimonio de los amantes y la defensa del honor de los personajes. De Silva obvia el elemento trágico y resuelve el conflicto planteado por Rojas instaurando un "final feliz." Es así como regresa al paradigma medieval y no lee la propuesta que subyace en la ambigüedad de Celestina: cada personaje tiene un destino individual que debe resolver al margen de los códigos fijados por las instituciones juzgadas decadentes.

¿Qué esperaba del texto celestinesco Feliciano de Silva? ¿Por qué leyó de una manera monológica Celestina? ¿Por qué cerró su sentido? ¿Por qué redujo a Celestina y a Melibea? Siguiendo a Jauss, el texto de Rojas provocaría en él una expectación que miró ambigua y una orientación peligrosa como ejemplo de moralidad. Así que intentó reorientar la lectura de sus contemporáneos y de los lectores futuros del texto, procurando encauzar el sentido hacia el epistema medieval, eliminando las conciencias de los personajes y quitando la ambigüedad, orientando el sentido hacia los valores del matrimonio, la honra y el cristianismo. Él observó una peligrosa salida hacia derroteros incomprensibles, por eso castró Celestina. No fue capaz de leer la transformación de un epistema, un cambio de valores, una "transición de época." El carácter conservador de su lectura-escritura 
se relaciona tanto con el miedo a los cambios como con su ceguera para comprender que escribía en un período histórico donde los valores que defendía ya estaban caducos y otros explicaban el mundo de nuevas maneras. Por último, tampoco supo que Fernando de Rojas había propuesto un nuevo paradigma de seres humanos del cual en la Segunda Celestina no asoma ni un sólo rasgo.

$* * *$

\section{NOTAS}

1 Tomo como corpus principal los actos IV y X, donde se desarrollan los procesos de seducción de Celestina; sin embargo, hago referencia, también, a otros pasajes de la Tragicomedia.

2 De la Segunda Celestina trabajo como corpus principal las cenas XX y XXVI, ya que es en ellas donde se plantean los procesos de seducción hacia Polandria, aunque, igualmente, hago referencia a otros pasajes del texto.

3 La edición que sigo es la de D. S. Severin (Madrid: Cátedra, 1994). Esta ed. toma como texto base la edición de Zaragoza 1507. Para suplir los pasajes de que adolece dicha ed. emplea la Comedia de Toledo 1500 y la Tragicomedia de Valencia 1514. En adelante cito por página de la ed. De Severin.

4 Prueba de ello es la confesión que hace este personaje a su padre en el acto $\mathrm{XX}$, cuando no tenía ya ningún motivo para mentir u ocultar nada, ya que estaba a un paso de suicidarse. Declara: “ [...] la qual [Celestina], de su parte venida a mí, sacó mi secreto amor de mi pecho; descobría a ella lo que a mi querida madre encobria" (333).

5 Lida de Malkiel considera que en Celestina se presentan tres tipos de procesos de seducción por parte de la alcahueta: el desarrollo de planes racionales para conseguir lo que desea, la improvisación en el ataque: cada situación puede ser punto de partida para nuevos razonamientos, y la acomodación estilística, que consiste en "hablarle [al interlocutor] en su propia lengua a fin de insinuarse mejor su voluntad: en Celestina, como en nadie, es el lenguaje arma para la acción" (1970, 524). En las estrategias que señalo es evidente que se presenta la estricta racionalidad de Celestina, así como una destacada capacidad de improvisación que procura seguir las respuestas de Melibea, y en todas ellas, es clara la gran elocuencia de la alcahueta para hablarle a cada quién de acuerdo con lo que espera oír.

6 Sigo a Severin en poner en cursiva los segmentos correspondientes a las interpolaciones de la Tragicomedia.

7 No creo en la intervención del demonio como fuerza necesaria para explicar los acontecimientos del texto. En esta situación sigo la interpretación de Joseph T. Snow, quien sostiene que: "Sin ver a Celestina en dos años, y con el recuerdo de una mujer necesitada a quien le solía dar algo, por necesitada y por vecina, y en el mismo momento, distraída por la enfermedad de su hermana y la presencia de un paje (señal además de que su visita urge), Alisa no tiene grandes razones para recordar los otros oficios de Celestina en ese instante (...). Es lógico, así visto el momento complicado, imaginar cuán fácil es para Alisa aceptar la realidad del pretexto del 
hilado y confiar en que Melibea, mujer de veinte años y siempre obediente y dócil, puede concluir el poco trato que queda del negocio: pagar el hilado según su calidad" $(1999,17)$.

8 Leyendo la organización estructural del acto IV, Carlos Rubio observa que el diálogo entre la doncella y la vieja "se organiza en tres períodos dramáticos proporcionados: (1) anticlímax, representado por las razones de Celestina sobre temas abstractos (vejez, riqueza) y por las alabanzas, "captatio benevolentiae"; (2) clímax dramático con la ira de Melibea al oír el nombre de Calisto; (3) postclímax con disculpas de la alcahueta, sus elogios a Calisto y las excusas de Melibea" (1978, 17).

9 Mercedes Alcalá Galán indica que: "La caracterización de Celestina como personaje pasa indefectiblemente por su identidad de madre que no lo es -su maternidad postiza, el ser llamada "madre" por todos, se basa en un acuerdo tácito de aparentar -y autoconvencerse - de la bondad y espontaneidad de sus relaciones con los demás, que siempre llevan el sello de lo ilícito. Su "maternidad" está, asimismo, caracterizada por la debilidad afectiva en ambas direcciones, tanto por parte de la madre como por parte de sus "hijos" que ven en la vieja un medio para conseguir fines deseados, fines independientes de ella como persona" $(1996,40)$.

${ }^{10}$ Celestina insiste en su estrategia de adulación de la belleza y de la condición social de Melibea llamándola "Donzella graciosa y de alto linage, tu suave habla y alegre gesto, junto con el aparejo de liberalidad que muestras con esta pobre vieja, me dan osadía a te lo dezir" (159).

11 Russell interpreta la oración de Santa Polonia y el cordón como elementos mágicos que intervienen en el comportamiento de Melibea. De la oración piensa que ésta facilita la philocaptio y del cordón indica que "según las teorías mágicas una prenda de vestir guardaba algo de la personalidad de la persona que solía llevarla. Celestina quiere el cordón de Melibea, tanto por el hecho de que había estado en íntimo contacto con el cuerpo de la muchacha como por la fuerza espiritual con que se lo suponía dotado debido a que había tocado las mencionadas reliquias fuerza que ahora será convertida por la magia a fines malignos" $(1991,318)$. No obstante, creo que no es necesaria la magia para explicar los comportamientos de Melibea, según vengo señalando.

12 María Rosa Lida señala que el "aire equívoco de la entrevista es indiscutible: si Melibea se aviene a entrar en el juego es porque, más o menos a sabiendas, ha decidido rendirse" $(1970,421)$.

13 Lo describe de la siguiente manera: "En Dios y en mi alma, no tiene hiel; gracias, dos mil; en franqueza, Alexandre; en esfuerço, Hétor; gesto, de un rey; gracioso, alegre; jamás reyna en él tristeza. De noble sangre, como sabes; gran justador. Pues verle armado, un sant Jorge. Fuerça y esfuerço, no tuvo Hércules tanta; la presencia y faciones, disposición, desemboltura, otra lengua avía menester para las contar; todo junto semeja ángel del cielo" (167).

14 Me parece acertada la opinión de María Eugenia Lacarra, quien considera que "es anacrónico imaginarla como un prototipo "avant la lettre" de la mujer liberada y rebelde. Su ejemplo no es positivo y "su caso" no sería admirable ni siquiera para nosotras. ¿Cómo identificarse con una mujer que se suicida por el amor de un hombre ridículo, de quien nos hemos reído a lo largo de toda la obra?, ¿cómo solidarizarnos 
con su amor, si en su egoísmo el amor se reduce al placer? ¿Cómo puede ser, en definitiva, trágico o rebelde un personaje sujeto al sarcasmo de prostitutas y criados y cuyo amante la ve como un pájaro a quien hay que desplumar antes de comer?" $(1989,26)$.

15 Este mecanismo, sostiene Lotman "no consiste en la coexistencia simultánea e inmóvil de diversos significados, sino en la conciencia permanente de otros significados distintos al que se percibe en un momento dado. El 'efecto lúdico' consiste en que los diferentes significados de un elemento no coexisten inmóviles, sino que 'tilitan' $(1988,92)$.

16 Dice el teórico: "no se debe convertir a un hombre vivo en un objeto carente de voz y de un conocimiento que lo concluya sin consultarlo. En el hombre siempre hay algo que sólo él mismo puede revelar en un acto libre de autoconciencia y de discurso, algo que no permite una definición exteriorizante e indirecta" (1985, 87).

17 Cuando en el acto XIV Melibea pierde su virginidad se lamenta de haberla perdido. Pero más le duele el deshonor que ha infligido a sus padres: “ $\mathrm{i} O$ pecadora de ti, mi madre, si de tal cosa fuesses sabidora, cómo tomarías de grado tu muerte y me la darías a mí por fuerça; cómo serías cruel verdugo de tu propia sangre; cómo sería yo fin quexosa de tus días! ¡ $\mathrm{O}$ mi padre honrrado, cómo he dañado tu fama y dado causa y lugar a quebrantar tu casa! ¡O traydora de mí, cómo no miré primero el gran yerro que se seguía de tu entrada, el gran peligro que sperava!" (286). Esta preocupación de Melibea, que ya está supeditada a su decisión de enamorada, muestra lo que María Rosa Lida ha señalado en el sentido de que "El ámbito de su angustia de enamorada no es su alma individual, antes se ensancha para abarcar la opinión de la ciudad -el honor y el recuerdo de todo su sexo, preso en la misma convención" (1970, 406-407).

18 Reinaldo Ayerbe-Chaux hace una lectura plana de Celestina a partir de la doctrina escolástica de la tentación y señala que "Celestina, siguiendo el mismo proceso que con Pármeno, destruye en primer lugar la 'conciencia intelectual' de la joven, subrayando lo limitado y cambiable de la misma, para luego, en la tentación propiamente dicha, despertar en ella la 'conciencia sentimental', esa conciencia del yo en busca del deleite" $(1978,5)$. Para el autor, se plantean en el texto los pasos de la tentación, la curiosidad, la vanagloria y la soberbia, para concluir que Rojas “describía el proceso de la caída de la amada en los únicos términos sicológicos entonces conocidos" $(1978,9)$. Una interpretación semejante realiza Eliézer Oyola, quien apunta que "es como si el pecado capital, materia prima del artista medieval, fuera condimentado y cocido hasta adquirir un nuevo y más sabroso sabor artístico, reflejado en la técnica dramática del autor de La Celestina" $(1979,243)$.

19 Este criterio lo sostiene Menéndez Pelayo cuando afirma que "no hay personaje alguno de La Celestina, aunque rara vez aparezca, que no muestre propia e inconfundible fisonomía" (1943a, 364).

20 María Rosa Lida considera que la libertad individual de Melibea le permite afirmar un sentido particular del honor que no es contrario al decoro: "ella, tan cuidadosa de la reputación aneja a su categoría social, viene a postergarla y descubrir así un honor individual que no contradice sino supera su primitivo sentimiento. Una vez admitido el tropiezo lógico en el proceder de Melibea el no resolverse a 
casar con Calisto, ni siquiera cuando está oyendo que su padre le permite elegir marido, fuerza es reconocer que su actitud no entraña falta de decoro incompatible con la Melibea de los actos anteriores, antes bien es muy propia del recio carácter de la doncella, ni incauta ni remilgada, que ya se ha rebelado contra la convención social que le veda descubrir (...) y satisfacer (...) su amor. (...) Melibea, sin ninguna coacción social, se torna por su propio albedrío esclava de su libre amor" (1970, 427 428).

21 Como indica Erna Ruth Berndt, "el sentimiento de Melibea adquiere una dimensión más por la conciencia que del mismo tiene y expresa” $(1963,64)$.

22 Mercedes Alcalá Galán sostiene que la muerte del personaje es una firme actitud de autodeterminación individual: "No se trata de una huida, sino de un acto supremo de rebeldía y autodeterminación. Su muerte es su triunfo, la salva del juicio de los demás. Melibea es esencialmente exhibicionista, como Calisto. Su final trágico es paradójicamente la culminación no de una entrega sino de una exitosa voluntad de poder, una afirmación de sí misma desafiante y relativamente meditada. Su autocompasión no es más que una justificación de su sacrificio; la obsesión por Calisto que la lleva a la muerte no es otra cosa que la única forma coherente que le queda de aferrarse a su nueva identidad recién creada" $(1996,53)$.

23 Gilman afirma esta misma idea cuando indica que "es evidente que Melibea siente que la vida no vale la pena de vivirse sin esa posibilidad de gozo, esa a la vez mística y carnal satisfacción sentimental, que le proporcionaba Calisto. (...) El amor por el amor con su fatal culto a la muerte cede aquí a una especie de proyecto personal de inmortalidad acompañada" $(1974,226)$.

24 D.W. McPheeters sostiene esta tesis cuando afirma: "Prefiere la muerte con Calisto a una vida sin él. La actitud y acciones de Melibea, como las de una heroína de Séneca, no son típicas de la época, pero ella encarna los conceptos cambiantes de la femenidad que van a influir en el período posterior del Renacimiento" $(1985,19)$.

25 De estos episodios opina Menéndez y Pelayo: “Atento Feliciano de Silva, como novelista de oficio que era, a dar variedad a su libro con todo género de salsas $e$ ingredientes, introdujo el ridículo episodio pastoril de Acays y Filinides, que es una de las primeras apariciones del bucolismo en la novela castellana, y remedó la media lengua de los negros de Guinea en los coloquios de dos esclavos, Zambrán y Boruca. Esta segunda novedad tuvo más éxito que la primera y fué imitada por muchos. No faltan, por supuesto, en este centón (que de tal puede calificarse la Segunda Celestina) bastantes versos menos que medianos, y varios cuentos" (1943b, 77). Criado de Val valora mejor que Menéndez Pelayo la Segunda Celestina, dice que "es obra importante de la literatura española. Representa la antítesis de la obra de Rojas, y en ciertos aspectos, su parodia. No es una simple imitación ni una continuación convencional. Prueba de ello es que llegó a tener en algún período más éxito que el de la propia "primera Celestina" $(1977,27)$. Opinión que, desde mi punto de vista, intenta equiparar en un mismo nivel valorativo dos textos muy diferentes con perspectivas ideológicas igualmente disímiles. Criado de Val no toma en consideración la abismal distancia estilística y estructural que separa a Silva de Rojas.

26 Feliciano de Silva. Segunda Celestina. Ed. Consolación Baranda. Madrid: 
Cátedra, 1988, 289. Esta edición se basa en el texto de Medina del Campo de 1534. En adelante, para citar esta edición indico la abreviatura SC (Segunda Celestina) y el número de página correspondiente.

27 Le advierte Lucrecia a Alisa: "iJesú, señora, más conoscida es esta vieja que la ruda!, no sé cómo no tienes memoria de la que empicotaron por hechizera, que vendía las moças a los abades y descasava mil casados" (152).

28 En Celestina la alcahueta pregunta a Alisa: “¿Y qué mal es el suyo?” a lo que responde Alisa: "Dolor de costado, y tal que, según del moço supe que quedava, temo no sea mortal. Ruega tú, vezina, por amor mío, en tus devociones por su salud a Dios" (154). Y Celestina le promete tenerla en sus oraciones.

${ }^{29}$ En Celestina, recuérdese que Celestina adula la belleza de Melibea diciéndole: " $\mathrm{i}$ angélica ymagen, o perla preciosa, y cómo te lo dizes!" (158).

${ }^{30}$ Para Félix Carrasco, este aspecto del suicido los imitadores se lo censuran a Rojas: "en Segunda Celestina, de Feliciano de Silva, cuando preguntan a Celestina por la suerte de Melibea, responde con evasivas por cautela, pero no deja de afirmar la posición cristiana ante el problema" $(1994,239)$.

${ }^{31}$ Evidente referencia a Celestina. Cuando la alcahueta le habla de la persona por la cual intercede a Melibea presenta a Calisto de la siguiente manera: "Yo dexo un enfermo a la muerte, que con sola una palabra de tu noble boca salida, que [le] lleve metida en mi seno, tiene por fe que sanará, según la mucha devoción tiene en tu gentileza" $(C, 159)$.

32 Véase la nota 13.

33 Le dice la alcahueta a Elicia: "Ora, sus, yo me voy a missa; y mira que aquel paje del infante no me entre en casa" (SC,563).

${ }_{34}$ En el último diálogo entre Felides y Polandria, cuando están planeando el matrimonio le indica el primero a Polandria: "que si yo puedo será antes de ocho días; y la vieja Celestina quiero que concierte lo acordado de nuestro casamiento, para aprobación de su mala estimación" (SC, 577), con lo cual Celestina, en vez de corruptora del honor, termina siendo casamentera.

35 De este aspecto tan débil de Polandria escribió María Rosa Lida "no puede darse figura más borrosa y arbitraria que la de Polandria, totalmente eclipsada por su doncella" $(1970,460)$.

36 Esta situación hizo decir a Menéndez Pelayo: "Hay verdadera delicadeza moral en el tipo de la criada y confidente Poncia, alegre y chancera, honestamente jovial, virtuosa sin afectación, llena de buen sentido no exento de cálculo. Ella salva a su ama de muchos peligros, la precave contra las imprudencias de su propio corazón, la alecciona en las situaciones difíciles, se defiende ella misma contra los arrebatos amorosos del paje Sigeril y ella es, y no Celestina, quien verdaderamente prepara el desenlace, en que la moral queda a salvo (...)" (1943b, 73).

${ }^{37}$ Para Jauss, esta noción debe entenderse como el sistema de referencias que surge para cada texto cuando se publica. Tal sistema se constituye de relaciones entre lo que el lector entiende por género literario, forma artística y temas de los textos conocidos anteriormente. De este conocimiento previo dependerá lo que el lector espere del nuevo texto, aunado al conjunto de señales y referencias que este texto le aporte. Esto constituye el horizonte de expectativas, el cual, como se observa, se materializa en dos niveles: el del conocimiento previo del lector y el del 
texto que surge: "El análisis de la experiencia literaria del lector se escapa entonces del psicologismo amenazante cuando describe la recepción y el efecto de una obra en el sistema referencial, objetivable, de las expectativas, que surge para cada obra en el momento histórico de su aparición, del conocimiento previo del género, de la forma y de la temática de obras conocidas con anterioridad y del contraste entre lenguaje poético y lenguaje práctico" (Jauss 1987, 57).

\section{BIBLIOGRAFÍA.}

Alcalá Galán, Mercedes. 1996. "Voluntad de poder en Celestina." Celestinesca. 20: 37-55.

Ayerbe-Chaux, Reinaldo. 1978. "La triple tentación de Melibea." Celestinesca. 2.2 (noviembre): 3-9.

Bajtín, Mijaíl. 1985. Estética de la creación verbal. Trad. Tatiana Bubnova. 2a ed. México: Siglo Veintiuno.

Berndt, Erna Ruth. 1963. Amor, muerte y fortuna en La Celestina. Madrid: Gredos.

Carrasco, Félix. 1994. 'La recepción de Celestina a mediados del siglo XVI: Evaluación de dos lecturas." Actas del III Congreso de la Asociación Hispánica de Literatura Medieval. Ed. M. I. Toro Pascua. Tomo I. Salamanca: Biblioteca Española del Siglo XV. Depto. de Literatura Española e Hispanoamericana, 233-240.

Criado de Val, Manuel. 1977. "Introducción” a: Fernando de Rojas. La Celestina. Ed. M. Criado de Val. Madrid: Editora Nacional, 7-38.

Gilman, Stephen. 1974. La Celestina: arte y estructura. Trad. Margit Frenk de Alatorre. Madrid: Taurus.

Jauss, Hans Robert. 1987. «Historia de la literatura como una provocación a la ciencia literaria.». En busca del texto. Teoría de la recepción literaria. Ed. Rall, Dietrich. Trad. Sadra Franco. México: UNAM, 55-58.

Lacarra Lanz, Eukene. 1999. "Calisto y el amor hereos." Insula. 54. 633 (setiembre): 20-22.

Lacarra, María Eugenia, 1989. "La parodia de la ficción sentimental en Celestina," Celestinesca 13.1 (mayo): 11-29.

Lida de Malkiel, María Rosa. 1970. La originalidad artística de 'La Celestina'. 2a edición. Buenos Aires: Editorial Universitaria de Buenos Aires.

Lotman, M. Yuri, 1988. Estructura del texto artístico. Trad. Victoriano Imbert. Madrid: Istmo.

Mc.Pheeters, D. W. 1985. Estudios bumanisticos sobre 'La Celestina'. Potomac MD: Scripta Humanística.

Menéndez Pelayo, Marcelino. 1943a . Orígenes de la novela. Tomo III. Madrid: Consejo Superior de Investigaciones Científicas. . 1943b . Orígenes de la novela. Tomo IV. Madrid: Consejo Superior de Investigaciones Científicas.

Oyola, Eliézer. 1979. Los pecados capitales en la literatura medieval española. 
Zaragoza: Puvill.

Rojas, Fernando de. 1994. La Celestina, Ed. D. S. Severin. Madrid: Cátedra, 1984.

Rubio, Carlos. 1978. "El juego de seducciones de La Celestina: una estructura dramática.. Celestinesca. 2.1 (mayo): 13-23.

Russell, Peter. 1991. "Introducción" a: Fernando de Rojas. Comedia o tragicomedia de Calisto y Melibea. Madrid: Castalia, 11-158.

Silva, Feliciano de. 1988. Segunda Celestina. Ed. Consolación Baranda. Madrid: Cátedra.

Snow, Joseph T. 1999. "Alisa, Melibea, Celestina y la magia," Insula. 54. 633 (setiembre): 15-18.

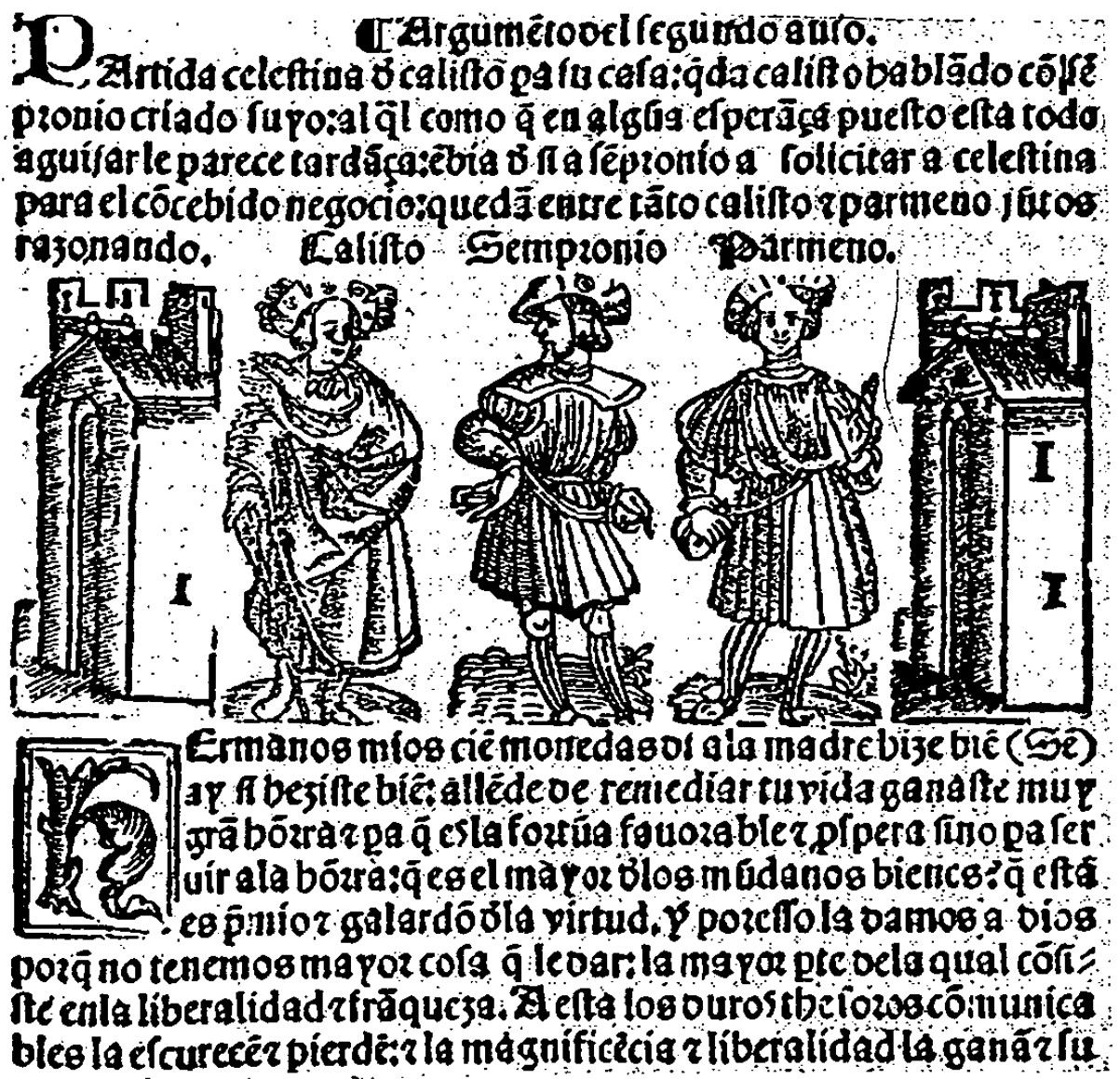

Toledo 1538 